\title{
BIOGRAFIAS NÃO AUTORIZADAS: UM ESTUDO DA ADI 4815
}

\author{
UNAUTHORIZED BIOGRAPHIES: AN STUDY OF THE ADI 4815
}

Marco Aurélio Rodrigues da Cunha e Cruz Wilson Antônio Steinmetz"*

Resumo: $O$ objetivo com este texto foi examinar a contribuição do julgado do Supremo Tribunal Federal sobre Biografias Não Autorizadas (ADI 4815) para o debate sobre a relação entre liberdade de expressão e direitos da personalidade. Adotou-se uma metódica analítica e reconstrutiva dos principais argumentos sucitados na ADI 4815. Inicialmente, fez-se uma análise da petição inicial para identificar os argumentos e os paradigmas normativos que a sustentam. Na sequência, realizou-se um comparativo analítico e crítico desses argumentos com as razões jurídicas que fundamentam a decisão do Supremo Tribunal Federal.

Palavras-chave: Biografias. Censura privada. Liberdade de expressão. Supremo Tribunal Federal.

\begin{abstract}
This text aimed to examine the contribution of the Supreme Court's Judgment on Unauthorized Biographies (ADI 4815) to the debate on the relationship between freedom of expression and rights of personality. It was adopted an analytical and reconstructive method of the main arguments raised in ADI 4815. Initially, an analysis of the initial petition was performed in order to identify the normative arguments and the paradigms that support it. Subsequently, it was made an analytical and critical comparison of these arguments with the legal reasons that justify the decision of the Federal Supreme Court.
\end{abstract}

Keywords: Biographies. Private censorship. Freedom of expression. Federal Court of Justice.

\footnotetext{
" Doutor e Mestre em Direito Constitucional pela Universidad de Sevilla, Espanha; Professor do Programa de Mestrado Acadêmico em Direito na Universidade do Oeste de Santa Catarina; Av. Nereu Ramos, 3777 D, Seminário, 89813-000; Chapecó, Santa Catarina, Brasil; mar.cunhaecruz@gmail.com

" Doutor e Mestre em Direito pela Universidade Federal do Paraná; Professor do Programa de Mestrado em Direito na Universidade de Caxias do Sul; Rua Francisco Getúlio Vargas, 1130, Bloco 58, Sala 210, Petrópolis, 95100-000, Caxias do Sul, Rio Grande do Sul, Brasil; wilson.steinmetz@gmail.com
} 


\section{Introdução}

Têm sido recorrentes na pauta do Supremo Tribunal Federal (STF), casos que põem em evidência a tensão entre a liberdade de expressão, o direito à informação e os direitos da personalidade. No entanto, o caso das Biografias Não Autorizadas oportunizou que a Corte, pela primeira vez, tivesse de fazer uma intrepretação de uma determinação normativa específica da Lei Civil (arts. 20 e 21 do Código Civil) à luz desses bens constitucionais: a autorização prévia para as biografias. A despeito de ser uma ação direta de inconstitucionalidade, vários casos concretos foram citados na decisão, o que denota a relevância jurídica e o impacto social das razões que fundamentaram o acórdão.

Nesse sentido, com este texto tem-se a intenção de realizar uma reconstrução argumentativa da $\mathrm{ADI}$ 4815. Na primeira parte deste trabalho tem-se por escopo uma análise dos argumentos da autora da ação, a Associação Nacional dos Editores de Livros (ANEL), para contextualizar e explicar como o caso das Biografias Não Autorizadas (ADI 4815, Relatora Min. Cármen Lúcia, Julgamento em 10 de junho de 2015, Tribunal Pleno, DJe-018 de 29 de janeiro de 2016, publicação em 01 de fevereiro de 2016) chegou ao STF. Após, enfrenta-se a questão de Direito em disputa, para identificar e explicar os fundamentos normativo-jurídicos implicados. Na sequência, o foco são as razões jurídicas invocadas pelo STF para depurar, analítica e criticamente, os fundamentos mais relevantes que sustentam a decisão.

\section{Os três argumentos da petição inicial da ADI 4815}

A ADI 4815 teve início em julho de 2012. A ANEL propôs a Ação Direta de Inconstitucionalidade, com pleito de medida cautelar, com a finalidade de que o Supremo Tribunal Federal (STF) declarasse a inconstitucionalidade parcial, sem redução de texto, dos artigos 20 e 21 da Lei n. 10.406/2002, Código Civil (CC/02). Alegou-se que com a interpretação dada a esses dispositivos legais pelo Poder Judiciário, a publicação e a veiculação de obras biográficas, literárias ou audiovisuais, estavam sendo proibidas em razão da ausência de prévia autorização dos biografados ou de pessoas retratadas como coadjuvantes (ou de seus familiares, em caso de pessoas falecidas). A principal tese que conduz a peça inaugural é esta: "[...] a dicção [dos artigos 20 e 21 do Código Civil] que lhes foi conferida acaba dando ensejo à proliferação de uma espécie de censura privada que é a proibição, por via judicial, das biografias não autorizadas." Essa tese, ao nosso ver, baseia-se em três argumentos, neste trabalho nominados como: argumento libertário, argumento mercantil e argumento do pluralismo.

$\mathrm{O}$ argumento libertário reclama a inconstitucionalidade da aludida interpretação por meio da aplicação da posição preferencial da proteção das liberdades de expressão e informação sobre a privacidade e a intimidade. Essa posição de preferência é fundamentada na peça inicial com base em duas razões. A primeira é que "[...] as pessoas cuja trajetória pessoal, profissional, artística, esportiva ou política, haja tomado dimensão pública, gozam de uma esfera de privacidade e intimidade naturalmente mais estreita", pois "[...] sua história de vida passa a confundir-se com a história coletiva, na medida da sua inserção em eventos de interesse público." Partindo dessa premissa, concluiu-se 
que "[...] exigir a prévia autorização do biografado (ou de seus familiares, em caso de pessoa falecida) importa consagrar uma verdadeira censura privada à liberdade de expressão dos autores, historiadores e artistas em geral, e ao direito à informação de todos os cidadãos." Aqui residiria a segunda razão da posição de preferência: a dupla dimensão da liberdade de expressão. Como direito subjetivo individual e como um direito difuso da cidadania, com supedâneo na democracia. Citaram-se como dispositivos violados os incs. IV, IX e XIV do art. $5^{\circ}$ da Constituição Federal de 1988 (CF/88).

$\mathrm{O}$ argumento mercantil ressalta que a anuência do biografado ou de sua família seria um "verdadeiro direito potestativo", pois produziria um "[...] efeito devastador sobre o mercado editorial e audiovisual: escritórios de representação negociam preços absurdos pelas licenças, transformando informação em mercadoria." A ANEL aduz que a necessidade de autorização prévia reflete uma "[...] disputa puramente mercantil, um verdadeiro leilão da história pessoal de vultos históricos, conduzido, muitas vezes, por parentes que jamais os conheceram."

$O$ argumento do pluralismo direciona a atenção para um terceiro fator da alegada inconstitucionalidade de interpretação. A ANEL adverte que o preço cobrado pela autorização prévia das biografias desestimula os historiadores e os autores em geral, do que decorreria um "[...] efeito silenciador e distorcivo dos relatos históricos e da produção cultural nacional." Essa atenuação informativa afetaria o pluralismo (político, histórico e cultural) previsto no art. $1^{\circ}$, inciso V, da CF/88, e "[...] representa, na prática, a antítese da ideia do pluralismo em relação às visões da história política, artística e social do país."

Sintetizados os principais pontos levantados na exordial da ANEL, cabe agora examinar a questão de Direito em disputa, a partir do fundamento normativo-jurídico afirmado no caso.

\section{A questão de direito em disputa}

No labor de explicar os dispositivos normativos afirmados pela autora da ação, a ANEL apontou textualmente os seguintes:

i) Os paradigmas normativos da $A D I 4815$ :

a. Argumento libertário. Art. $5^{\circ}$ incs. IV, IX, XIV da CF/88:

Art. $5^{\circ}$ Todos são iguais perante a lei, sem distinção de qualquer natureza, garantindo-se aos brasileiros e aos estrangeiros residentes no País a inviolabilidade do direito à vida, à liberdade, à igualdade, à segurança e à propriedade, nos termos seguintes:

$[\ldots]$

IV - é livre a manifestação do pensamento, sendo vedado o anonimato;

$[\ldots]$

$\mathrm{V}$ - é assegurado o direito de resposta, proporcional ao agravo, além da indenização por dano material, moral ou à imagem;

$[\ldots]$

IX - é livre a expressão da atividade intelectual, artística, científica e de comunicação, independentemente de censura ou licença;

$[\ldots]$ 
X - são invioláveis a intimidade, a vida privada, a honra e a imagem das pessoas, assegurado o direito à indenização pelo dano material ou moral decorrente de sua violação;

$[\ldots]$

XIV - é assegurado a todos o acesso à informação e resguardado o sigilo da fonte, quando necessário ao exercício profissional;

$[\ldots]$

b. Argumento do pluralismo. Art. 1, inc. V, da CF/88:

Art. $1^{\circ}$ A República Federativa do Brasil, formada pela união indissolúvel dos Estados e Municípios e do Distrito Federal, constitui-se em Estado Democrático de Direito e tem como fundamentos:

$[\ldots]$

V - o pluralismo político.

ii) O objeto da ADI 4815: os artigos 20 e 21 da Lei n. 10.406/2002 CC/02:

Art. 20. Salvo se autorizadas, ou se necessárias à administração da justiça ou à manutenção da ordem pública, a divulgação de escritos, a transmissão da palavra, ou a publicação, a exposição ou a utilização da imagem de uma pessoa poderão ser proibidas, a seu requerimento e sem prejuízo da indenização que couber, se lhe atingirem a honra, a boa fama ou a respeitabilidade, ou se se destinarem a fins comerciais.

Parágrafo único. Em se tratando de morto ou de ausente, são partes legítimas para requerer essa proteção o cônjuge, os ascendentes ou os descendentes.

Art. 21. A vida privada da pessoa natural é inviolável, e o juiz, a requerimento do interessado, adotará as providências necessárias para impedir ou fazer cessar ato contrário a esta norma.

iii) O pedido da ADI 4815:

[...] seja declarada a inconstitucionalidade parcial, sem redução de texto, dos artigos 20 e 21 do Código Civil para que, mediante interpretação conforme a Constituição, seja afastada do ordenamento jurídico brasileiro a necessidade do consentimento da pessoa biografada e, a fortiori, das pessoas retratadas como coadjuvantes (ou de seus familiares, em caso de pessoas falecidas) para a publicação ou veiculação de obras biográficas, literárias ou audiovisuais.

Caso assim não se entenda, por mera eventualidade, a ANEL pede seja declarada a inconstitucionalidade parcial, sem redução de texto, dos artigos 20 e 21 do Código Civil para que, mediante interpretação conforme a Constituição, seja afastada do ordenamento jurídico brasileiro a necessidade do consentimento da pessoa biografada e, a fortiori, das pessoas retratadas como coadjuvantes (ou de seus familiares, em caso de pessoas falecidas) para a publicação ou veiculação de obras biográficas, literárias ou audiovisuais elaboradas a respeito de pessoas públicas ou envolvidas em acontecimentos de interesse coletivo.

Nota-se, pois, que não foi assinalado um paradigma normativo para o argumento mercantil. $\mathrm{Na}$ verdade, tampouco na petição foram apresentados ou levantados dados que subsidiassem esse argumento. Muitos questionamentos poderiam ser suscitados, como o direito de fruição econômica da própria história pelo biografado (e sucessores) e o destino dos proveitos econômicos das biografias por parte dos editores e dos biógrafos (mercado editorial e audiovisual). Ainda que fosse interessante 
o debate sobre o aspecto econômico da autorização prévia de biografias na $\mathrm{ADI}$ 4815, não foi tão decisivo, como se verá, para o deslinde decisório. Por esse motivo, não faz parte do escopo deste trabalho.

Sem embargo, sobre o argumento libertário houve uma justificação maior na peça inaugural da $\mathrm{ADI} 4815$, com recurso discursivo à dupla dimensão da liberdade de expressão e da sua posição preferencial. Entendeu-se por bem conferir autonomia ao argumento do pluralismo, a despeito de, na peça, ter sido derivado da dimensão difusa da liberdade de expressão (argumento libertário), pois foi indicado um paradigma normativo pela ANEL.

O questionamento a ser feito é se esses três argumentos obtiveram ressonância nas razões jurídicas da decisão do STF. Em nossa opinião, as razões jurídicas mais relevantes adotadas pela Corte para fundamentar a sua decisão são extraídas, primordialmente, do voto da relatora, que foi seguida por todos os colegas de Corte. A Ministra Cármem Lúcia inicia sua argumentação com um reforço sobre a contrariedade à censura. Após relatar as posições tomadas na audiência pública ${ }^{1}$ que fora realizada, aponta algumas definições sobre direito à liberdade de expressão, direito à informação, direito à intimidade e direito à privacidade, que conformam os pressupostos do seu juízo. Posteriormente, tematiza seu voto na proibição da censura prévia, para, ao final, estipular o conceito de biografia e suas digressões. A conclusão é pela procedência do pedido. Nesse sentido, a seguir há uma listagem das razões jurídicas com seus respectivos fundamentos, para cotejá-las com os três argumentos anteriormente aludidos.

\section{Razão jurídica 1 ( $R J 1)$ : as proteções constitucionais da liberdade de expressão e do direito à informação}

A proposta argumentativa da $R J 1$, segundo o voto da relatora, arvora-se na liberdade de expressão, no direito de liberdade de expressão, no direito à informação e na responsabilidade constitucional pela informação. A liberdade de expressão teria concepção mais ampla, transitando em vários campos do conhecimento, tendo como exemplos a filosofia, a literatura e a religião. Sobre o direito à liberdade de expressão, sustenta que é

[...] outra forma de afirmar-se a liberdade do pensar e expor o pensado ou o sentido, acolhida em todos os sistemas constitucionais democráticos. A atualidade apresenta desafios novos quanto ao exercício desse direito. A multiplicidade dos meios de transmissão da palavra e de qualquer forma de expressão sobre o outro amplia as definições tradicionalmente cogitadas nos ordenamentos jurídicos e impõe novas formas de pensar o direito de expressar o pensamento sem o esvaziamento de outros direitos, como o da intimidade e da privacidade. Em toda a histó-

\footnotetext{
Dezesseis órgãos e entidades se manifestaram no processo: 1. Ministério Público Federal; 2. Academia Brasileira de Letras; 3. Associação Brasileira dos Constitucionalistas Democratas; 4. União Brasileira de Escritores; 5. Universidade Federal do Rio de Janeiro; 6. Associação Brasileira de Produtoras Independentes de Televisão; 7. Comissão de Direito Autoral da Ordem dos Advogados - Seccional de São Paulo; 8. Instituto Palavra Aberta; 9. Sindicato Interestadual da Indústria Áudio Visual; 10. Sindicato Nacional dos Editores de Livros; 11. Instituto Histórico e Geográfico Brasileiro; 12. Ministério da Cultura; 13. Associação Eduardo Banks; 14. Conselho de Comunicação Social do Congresso Nacional; 15. Associação Paulista de Imprensa; 16. Ordem dos Advogados do Brasil.
} 
ria da humanidade, entretanto, o fio condutor de lutas de direitos fundamentais é exatamente a liberdade de expressão.

Essa linha de pensamento leva o direito à liberdade de expressão a afirmar a liberdade do pensar e expor o que se pensa ou o que se sente. Esse direito encontraria ressonância nos Estados Democráticos de Direito. Consolidam esse direito várias declarações de direitos internacionais, como o art. XI da Declaração de Direitos do Homem e do Cidadão, o art. 19 da Declaração Universal dos Direitos Humanos da ONU, de 1948, o art. 10 da Convenção Europeia de Direitos Humanos, de 1953, o art. 19 do Pacto Internacional dos Direito Civis e Políticos da ONU, de 1966, o art. 13 da Convenção Americana de Direitos Humanos, de 1969, o art. $9^{\circ}$ da Carta Africana de Direitos Humanos e dos Povos, de 1986, e o art. 11 da Carta dos Direitos Fundamentais da União Europeia, de 2000.

No direito constitucional brasileiro, a Min. Relatora citou o direito de liberdade de expressão no art. 179, IV, da Carta Imperial de 1824; no art. 72, \12, da Constituição de 1891; no art. 113, 9, da Constituição de 1934; no art. 122, 15, da Constituição de 1937; no art. 141, \5 da Constituição de 1946; no art. 150, \8ª da Constituição de 1967; e no art. 153, \8, Emenda n. 1 de 1969. Há um reforço histórico no itinerário textual dos atos institucionais que se sobrepuseram a essas positivações constitucionais do direito de liberdade de expressão. Tais atos serão expostos na catalogação da próxima razão jurídica: a censura.

Com efeito, a Ministra Carmem Lúcia observa que o direito à liberdade de expressão pode ser lido nos incs. IV, V, IX, X e XIV do art. $5^{\circ}$ da CF/88. Ressalta que a questio iuris também reclama os contornos do direito à informação, previsto no inciso XIV do mesmo artigo $5^{\circ}$ e vinculado pela Min. relatora "[...] à proteção a obter e divulgar informação sobre dados, qualidades, fatos, de interesse da coletividade, ainda que sejam assuntos particulares, porém com expressão ou de efeitos coletivos." conceito desse direito seria

[...] o direito constitucionalmente garantido contempla a liberdade de informar, de se informar e de ser informado. $O$ primeiro refere-se à formação da opinião pública, considerado cada qual dos cidadãos que livremente poderá receber dados sobre assuntos de interesse da coletividade e sobre as pessoas cujas ações, público-estatais ou público-sociais, que possam interferir no direito de saber, de aprender sobre temas relacionados a cogitações legítimas.

O direito de ser informado concerne àquele que recebe o teor da comunicação, tornando-se ator no processo de liberdade crítica e responsável por suas opiniões e, a partir delas, por suas ações. Liberdade desinformada é algema mental transparente, porém tão limitadora quanto os grilhões materiais. A corrente da desinformação não é visível, mas é sensível na cidadania ativa e participativa. Como em Brecht, o pior analfabeto é o analfabeto político. O direito de ser informado é a garantia da superação do analfabetismo político.

$\mathrm{O}$ direito de se informar relaciona-se à liberdade de buscar a informação em fonte não censurada e sobre qualquer tema de interesse do cidadão. Coartar a busca livre de assunto ou em fonte circunscrita antecipadamente significa limitar a liberdade de obter dados de conhecimento para a formação de ideias e formulação de opiniões.

O direito fundamental constitucionalmente assegurado compreende a busca, o acesso, o recebimento, a divulgação, a exposição de dados, pensamentos, formulações, sendo todos e cada um responsáveis pelo que exorbitar a sua esfera de direitos e atingir outrem. 
A despeito de ser um direito, a Min. Relatora também sublinha a responsabilidade constitucional pela informação, fundada no inc. V, do art. $5^{\circ}$, da CF/88. Argumenta que a democracia exige a responsabilização pelo excesso:

A informação, a exposição e a divulgação de dado podem gerar dano como qualquer outro agir humano. Inúmeras vezes este Supremo Tribunal debruçou-se sobre esse tema e concluiu, com fundamento em normas constitucionais e legais, que a responsabilização compõe o sistema de liberdades (ADPF n. 130, Relator o Ministro Ayres Britto, Plenário, DJ 13.11.2009; AI n. 595.395/SP, Relator o Ministro Celso de Mello, decisão monocrática, DJ 3.8.2007; Rcl n. 9.428/DF, Relator o Ministro Cezar Peluso, Plenário, DJ 25.6.2010; ADI n. 4.451-MC-REF/DF, Relator o Ministro Ayres Britto, Plenário, DJ 24.8.2012; e RE n. 511.961/SP, Relator o Ministro Gilmar Mendes, DJ 13.11.2009)

$[\ldots]$

o exercício do direito às liberdades não se concilia com restrições ao direito de informar, menos ainda com a sua eliminação. Deve-se reivindicar sempre a responsabilidade democrática, princípio de cumprimento igualmente garantido.

Como se denota, a RJ1 (liberdade de expressão, direito de liberdade de expressão, direito à informação e responsabilidade constitucional pela informação) guarda, em certa medida, conexão com o argumento libertário levantado pela ANEL. A Min. Relatora não adota explicitamente o pressuposto da posição preferencial da liberdade de expressão sobre a intimidade e a vida privada, tampouco a maioria dos demais Ministros. Quem adere a essa tese é o Min. Luís Roberto Barroso, que afirma que a posição preferencial da liberdade de expressão não implica uma hierarquização de direitos fundamentais, mas, sim, uma transferência de ônus argumentativo: "Quem desejar afastar a liberdade de expressão é que tem que ser capaz de demonstrar as suas razões, porque, prima facie, em princípio, é ela, a liberdade de expressão, que deve prevalecer."

Em abono desse argumento há três pilares: a liberdade de expressão no Brasil há de ser "[...] afirmada e reafirmada, eventualmente, com certo exagero" em decorrência de sua acidentada história, marcada pela censura; a liberdade de expressão é um pressuposto democrático para o exercício dos outros direitos fundamentais, pois "[...] sem liberdade de expressão, não existe plenitude dos outros direitos, não existe autonomia privada, não existe autonomia pública"; "[...] a liberdade de expressão é essencial para o conhecimento da história, para o aprendizado com a história, para o avanço social e para a conservação da memória nacional." Com a adoção da posição preferencial da liberdade de expressão, o Min. Barroso observa que são três as consequências: uma primazia prima facie, pois se exige o ônus argumentativo de demonstrar a superação da preferência da liberdade de expressão; "[...] a forte suspeição e o escrutínio rigoroso que devem sofrer quaisquer manifestações de cerceamento da liberdade de expressão, seja legal, seja administrativa, seja judicial, ou seja privada"; a regra da proibição da censura prévia ou da licença. Quanto a essa, nem é necessária muita elaboração teórica, porque a Constituição, em cláusula expressa em dois lugares, proíbe terminantemente a censura.

Não obstante a proposta explícita do Min. Luís Roberto Barroso da aplicação da posição preferencial da liberdade de expressão, não se lê nos votos dos demais Ministros que essa tese in- 
fluenciou decisivamente a razão de decidir do STF na ADI 4815. Logo, do cotejo entre a totalidade do argumento libertário com a RJ1, infere-se que há em comum entre os dois somente a proteção constitucional da liberdade de expressão e do direito à informação.

\section{Razão jurídica 2 (RJ2): a proibição da censura}

"A Constituição do Brasil proíbe qualquer censura. $O$ exercício do direito à liberdade de expressão não pode ser cerceada pelo Estado ou por particular." Esse é o item 3 da ementa da ADI 4815, lavrada pela Min. Carmem Lúcia, relatora. Sobre esse pressuposto se entroncam várias ideias no seu voto, que foi decisivo na resolução dessa ação constitucional.

A relatora aborda literalmente a censura legal do Decreto Legislativo n. 34, formalizado no Decreto-Lei n. 1.077, de 26 de janeiro de 1970, que dispunha sobre a execução do artigo 153 , § $8^{\circ}$, parte final, da Emenda n. 1, de 17 de outubro de 1969. Os "considerandos" deste são bem apropriados para o raciocínio desenvolvido, pelo que é conveniente fazer citação direta:

O PRESIDENTE DA REPÚBLICA, usando da atribuição que lhe confere o artigo 55, inciso I da Constituição e CONSIDERANDO que a Constituição da República, no artigo 153 , $\int 8^{\circ}$ dispõe que não serão toleradas as publicações e exteriorizações contrárias à moral e aos costumes; CONSIDERANDO que essa norma visa a proteger a instituição da família, preserva-lhe os valôres éticos e assegurar a formação sadia e digna da mocidade; CONSIDERANDO, todavia, que algumas revistas fazem publicações obscenas e canais de televisão executam programas contrários à moral e aos bons costumes; CONSIDERANDO que se tem generalizado a divulgação de livros que ofendem frontalmente à moral comum; CONSIDERANDO que tais publicações e exteriorizações estimulam a licença, insinuam o amor livre e ameaçam destruir os valores morais da sociedade Brasileira; CONSIDERANDO que o emprêgo dêsses meios de comunicação obedece a um plano subversivo, que põe em risco a segurança nacional.

DECRETA:

Art. $1^{\circ}$ Não serão toleradas as publicações e exteriorizações contrárias à moral e aos bons costumes quaisquer que sejam os meios de comunicação.

Art. $2^{\circ}$ Caberá ao Ministério da Justiça, através do Departamento de Polícia Federal, verificar, quando julgar necessário, antes da divulgação de livros e periódicos, a existência de material infringente da proibição enunciada no artigo anterior.

Parágrafo único. O Ministro da Justiça fixará, por meio de portaria, o modo e a forma da verificação prevista neste artigo.

Art. $3^{\circ}$ Verificada a existência de matéria ofensiva à moral e aos bons costumes, o Ministro da Justiça proibirá a divulgação da publicação e determinará a busca e a apreensão de todos os seus exemplares.

Art. $4^{\circ}$ As publicações vindas do estrangeiro e destinadas à distribuição ou venda no Brasil também ficarão sujeitas, quando de sua entrada no país, à verificação estabelecida na forma do artigo $2^{\circ}$ dêste Decreto-lei.

Art. $5^{\circ} \mathrm{A}$ distribuição, venda ou exposição de livros e periódicos que não hajam sido liberados ou que tenham sido proibidos, após a verificação prevista neste Decreto-lei, sujeita os infratores, independentemente da responsabilidade criminal: I - A multa no valor igual ao do preço de venda da publicação com o mínimo de NCr\$10,00 (dez cruzeiros novos);

II - À perda de todos os exemplares da publicação, que serão incinerados a sua custa. 
Art. $6^{\circ} \mathrm{O}$ disposto neste Decreto-Lei não exclui a competência dos Juízes de Direito, para adoção das medidas previstas nos artigos 61 e 62 da Lei número 5.250, de 9 de fevereiro de 1967.

Art. $7^{\circ} \mathrm{A}$ proibição contida no artigo $1^{\circ}$ dêste Decreto-Lei aplica-se às diversões e espetáculos públicos, bem como à programação das emissoras de rádio e televisão. Parágrafo único. O Conselho Superior de Censura, o Departamento de Polícia Federal e os juizados de Menores, no âmbito de suas respectivas competências, assegurarão o respeito ao disposto neste artigo.

Art. $8^{\circ}$ Êste Decreto-Lei entrará em vigor na data de sua publicação, revogadas as disposições em contrário.

Brasília, 26 de janeiro de 1970; $149^{\circ}$ da Independência e $82^{\circ}$ da República.

EMÍLIO G. MÉDICI, Alfredo Buzaid.

A argumentação contra a censura ancora-se no paradigma normativo dos incisos IV, V, IX, X e XIV do artigo $5^{\circ}$ e do artigo 220 e seus parágrafos. ${ }^{2}$ A partir desses dispositivos normativos, formula-se o seguinte conceito de censura:

Censura é forma de controle da informação: alguém, não o autor do pensamento e do que quer se expressar, impede a produção, a circulação ou a divulgação do pensamento ou, se obra artística, do sentimento. Controla-se a palavra ou a forma de expressão do outro. Pode-se afirmar que se controla o outro. Alguém - o censor - faz-se senhor não apenas da expressão do pensamento ou do sentimento de alguém, mas também - o que é mais - controla o acervo de informação que se pode passar a outros.

[...]

A censura é frequentemente relacionada ao ilegítimo e perverso atuar do Estado. Prática comum em regimes autoritários ou totalitários, não é, contudo, exclusividade do Estado. A censura permeia as relações sociais, propaga-se nas circunstâncias da vida, recorta a história, reinventa o experimentado, pessoal ou coletivamente, omite fatos que poderiam explicitar a vida de pessoa ou de povo em diferentes momentos e locais. Censura é repressão e opressão. Restringe a informação, limita o acesso ao conhecimento, obstrui o livre expressar o pensado e o sentido.

Essas premissas das quais parte o raciocínio da Min. Carmem Lúcia reforçam a vedação da censura legislativa, administrativa ou judicial e igualmente justificam a proibição da censura quando proveniente de particulares. Argumenta que desde o Índex da Igreja Católica ao McCartismo nos Estados Unidos, de Giordano Bruno ao affaire Charlie Hebdo, são duas as características da censura estatal ou particular: "[...] a intolerância à diferença e à sobranceria de uma em relação à outra pessoa, sobre a qual se pretende exercer o poder." Identifica que o "Discurso do Politicamente correto" ("políticas tendentes a tornar a linguagem neutra para se evitar ofensa a pessoas ou grupos sociais discriminados historicamente") pode constituir forma de censura se adotadas "[...] formas de censura que mitigam ou dificultam o pluralismo ao qual a liberdade pessoal conduz, porque a censura, estatal ou particular, introduz o medo de não ser bem acolhido no grupo social." (grifo nosso).

\footnotetext{
2 Art. 220. A manifestação do pensamento, a criação, a expressão e a informação, sob qualquer forma, processo ou veículo não sofrerão qualquer restrição, observado o disposto nesta Constituição. $\ 1^{\circ}$ Nenhuma lei conterá dispositivo que possa constituir embaraço à plena liberdade de informação jornalística em qualquer veículo de comunicação social, observado o disposto no art. $5^{\circ}, \mathrm{IV}, \mathrm{V}, \mathrm{X}, \mathrm{XIII}$ e XIV. $\$ 2^{\circ}$ É vedada toda e qualquer censura de natureza política, ideológica e artística. [...] $\int 6^{\circ}$ A publicação de veículo impresso de comunicação independe de licença de autoridade.
} 
Com essas afirmações, há a justificativa de vedação à censura privada baseada na vinculação dos particulares aos direitos fundamentais porque a "[...] doutrina e jurisprudência reconhecem que a eficácia dos direitos fundamentais espraia-se nas relações entre particulares. [...] A proteção dos direitos não se limita à ação estatal, mas estende-se também à ação dos particulares nas relações intersubjetivas."

Sem embargo, indica que a Convenção Americana sobre Direitos Humanos se refere à censura prévia no art. 13 exclusivamente nos casos de proteção moral da infância e da adolescência. Sobre a vedação da censura estatal ou particular na Constituição de 1988, a Min. relatora aduz que

O sistema constitucional brasileiro traz, em norma taxativa, a proibição de qualquer censura, valendo a vedação ao Estado e a particulares. Assentou-se a horizontalidade da principiologia constitucional, aplicável a entes estatais ou a particulares, ou seja, os princípios constitucionais relativos a direitos fundamentais não obrigam apenas os entes e órgãos estatais, mas também são de acatamento impositivo e insuperável de todos os cidadãos em relação aos demais. O exercício do direito à liberdade de expressão não pode ser cerceado pelo Estado nem pelo vizinho, salvo nos limites impostos pela legislação legítima para garantir a igual liberdade do outro, não a ablação desse direito para superposição do direito de um sobre o outro.

O voto condutor da ADI 4815 observa ser proibida, igualmente, a censura prévia. Essa premissa foi sustentada na Declaração de Princípios sobre a Liberdade de Expressão, elaborada pela Comissão Interamericana de Direitos Humanos, e no caso Olmedo Bustos e outros versus Chile (2001), da Corte Interamericana de Direitos Humanos. Por sua vez, o Min. Barroso argumenta que

[...] a censura prévia e a licença prévia são vedadas pela Constituição Brasileira como regra geral, de modo que, em qualquer sanção pelo uso abusivo da liberdade da expressão - que pode ocorrer -, deve-se dar preferência para os mecanismos de reparação a posteriori e não impeditivas da veiculação da fala da manifestação.

Não obstante a vedação à censura, admite-se a possibilidade de limitações à liberdade de expressão. Essa assertiva é fundamentada no Estudo especial sobre o direito de acesso à informação da Relatoria Especial para a Liberdade de Expressão da Organización de los Estados Americanos (2007), o qual aponta que essas limitações podem ser fundadas na proteção dos direitos ou da reputação de outras pessoas, da segurança nacional, da ordem pública e da saúde e moral públicas.

Ao teor do exposto, pode-se dizer que, muito embora os dois Ministros não tenham utilizado o paradigma normativo da petição inicial da ANEL (art. $1^{\circ}, \mathrm{V}, \mathrm{CF} / 88$ ), o argumento do pluralismo foi utilizado para, de certa forma, configurar a RJ2. A Min. Carmem Lúcia comenta o caso Handyside, de 1976, julgado pela Corte Europeia de Direitos Humanos, em que se aborda o art. 10.2 da Convenção Europeia de Direitos Humanos como um dos fundamentos de uma sociedade democrática, incluídos entre eles o pluralismo e a tolerância. $\bigcirc$ Min. Barroso endossa essa posição, pois admite que "[...] a liberdade de expressão não deve proteger somente ideias positivas, socialmente aceitas, inofensivas e neutras, mas também aquelas negativas, ofensivas, incômodas e chocantes. Essa é uma exigência do pluralismo e da tolerância, essencial em uma sociedade democrática." Também cita a 
Corte Europeia de Direitos Humanos no caso Lingens v. Áustria, em que as razões da decisão também se basearam no pluralismo e na tolerância.

\section{Razão jurídica 3 ( $R J 3$ ): a autorização prévia para a biografia constitui censura prévia particular}

Biografia é história. A vida não se desenvolve apenas a partir da soleira da porta de casa. Autorização prévia para biografia constitui censura prévia particular. $O$ recolhimento de obras é censura judicial, a substituir a da administrativa. O risco é próprio do viver. Erros corrigem-se segundo o direito, não se coartando liberdades conquistadas. A reparação de danos e o direito de resposta devem ser exercidos nos termos da lei.

A construção das razões jurídicas antecessoras confluem para a Razão Jurídica 3 (RJ3): a autorização prévia para a biografia constitui censura prévia particular. Com efeito, a principal linha propositiva da petição da ANEL, como já transcrito, é que "[...] a dicção (dos artigos 20 e 21 do Código Civil) que lhes foi conferida acaba dando ensejo à proliferação de uma espécie de censura privada que é a proibição, por via judicial, das biografias não autorizadas." Nota-se uma inequívoca convergência entre a RJ3 e a principal tese que sustenta a propositura da ADI 4815.

Não obstante essa irrefutável constatação, é necessário examinar quais foram os fundamentos que embasaram a RJ3. Verifica-se que há uma intrínseca vinculação do conceito de biografia com os conceitos de intimidade, privacidade, honra e imagem, definidos pela Min. Carmem Lúcia:

Também garante a inviolabilidade da intimidade (a essência resguardada de cada um), da privacidade (o que não se pretende viver senão no espaço mais recolhido daqueles com quem recai a escolha), da honra (que se projeta a partir da formação moral e dos valores que determinam as ações de cada um e fazem a pessoa reconhecida, para o que se precisa da liberdade) e da imagem (construída a partir da livre escolha do que se quer ser). Se houver ofensa, - o que pode acontecer, pelas características humanas - o autor haverá de responder por essa transgressão, na forma constitucionalmente traçada, pela indenização reparadora ou outra forma prevista em lei.

Parece que a Min. relatora tende a separar os conceitos de "intimidade" e "privacidade". E mais: aproxima "vida privada" (expressão prevista na Constituição Federal) de "privacidade". Aduz ser "intimidade":

Etimologicamente, intimidade vem de timo - glândula situada na altura do coração e que identificaria a essência ou a vocação da pessoa. De timo vem a palavra que marca o que, sendo tão próprio e único, somente ao indivíduo pertenceria. Pelo que não haveria como deixar de reconhecê-la como dimensão da vida resguardada na dignidade pessoal e indevassável pela ação de outro, inviolável em sua projeção além da vontade do sujeito.

Por sua vez, a "privacidade"

[...] contrapõe-se à publicidade, constitui o que não se dá a público, por escolha de espaço próprio do controle das informações e dos dados sobre a vida da pessoa. 
Esses conceitos, entretanto, não são unanimemente aceitos, continuando controversa, na doutrina, a sua significação.

Segundo o voto vencedor, a diferenciação conceitual entre intimidade e privacidade não é inútil. Dá-se por duas razões:

A primeira refere-se à circunstância constitucional de se distinguirem intimidade e privacidade para os fins de definição do seu conteúdo na forma protegida no sistema jurídico fundamental brasileiro e de sua eficácia social.

A segunda respeita a esfera de sua definição, que não é a mesma para todos, pois o maior ou menor resguardo de espaço indevassável da vida pessoal aos olhos dos outros altera-se de acordo com a escolha feita pelo sujeito de direito a submeter-se à atividade que a) componha, ou não, os quadros de agentes das instituições estatais, sujeitas estas à transparência plena para ciência e controle dos cidadãos. Vem dos Antigos que aquele que não se quer expor ao público há de se manter nos umbrais da porta de casa, em cujo espaço, naquele período histórico, era sinônimo de segredo; b) promova as suas atividades em público e para o público, do qual extraia a sua condição profissional e pessoal, difíceis como são os lindes de uma e outra quando o nome, a profissão ou a função extraem do público o seu desempenho e do qual dependa o seu êxito. Quem busca a luz não há de exigir espaço intocado de sombra; ou c) extraia ou retire dos cidadãos, pelo exercício de sua função ou atividade, os ganhos materiais, profissionais ou de reconhecimento, com os quais se dá a viver, pelo que há de ser por eles conhecido.

Em qualquer dessas hipóteses, o indivíduo sujeita-se - quando não busca - conhecimento e reconhecimento público, não se podendo negar a tolerar, quando não quiser, que esse mesmo público busque dele conhecer. Não se há de pretender, assim, contar com o mesmo espaço de indevassabilidade que fixa os limites da privacidade de alguém que nada quer nem pretende do público em sua condução de vida.

Essa distinção parece ser decisiva como fundamento para a RJ3. Isso porque a biografia somente será referente a personagens que se sujeitam ou buscam conhecimento e reconhecimento público "[...] não se podendo negar a tolerar, quando não quiser, que esse mesmo público busque dele conhecer":

A biografia é a escrita (ou o escrito) sobre a vida de alguém, relatando-se o que se apura e se interpreta sobre a experiência mostrada e que, não sendo mostrada voluntariamente, não foi autorizada pelo sujeito ou por seus familiares a ser transmitida para a coletividade.

$[\ldots]$

O biógrafo busca saber quem é o biografado pesquisando a vida deste. Investiga, prescruta, indaga, questiona, observa, analisa, para concluir o quadro da vida, o comportamento não mostrado que ostenta o lado que completa o ser autor da obra que influencia e marca os outros. A vida do outro há de ser preservada. A curiosidade de todos há de ser satisfeita. O biógrafo cumpre o segundo papel.

$[\ldots]$

Afirmou-se, no curso desta ação, que a biografia não estaria cerceada, apenas dependeria de autorização, porque as versões apresentadas poderiam comprometer a intimidade e a privacidade do biografado.

O argumento não convence: primeiro, porque a expressão é livre. Qualquer censura prévia é vedada no sistema. A autorização prévia constitui censura prévia particular. O recolhimento de obras após a divulgação é censura judicial, que apenas substitui a administrativa. 
Segundo, a biografia autorizada é uma possibilidade que não exaure a possibilidade de conhecimento das pessoas, comunidades, costumes e histórias. Entre a história de todos e a narrativa de um, opta-se pelo interesse de todos.

Terceiro, a biografia autorizada não está proibida. Está não apenas permitida como pode ser estimulada. Deve-se levar em conta que a memória é traiçoeira. $O$ mesmo fato pode ser lembrado com mecanismos cerebrais que impõem a seleção e até a recriação de fatos e casos que não foram o que a interpretação da pessoa sugere. Não se há de frustrar a história pela lembrança elaborada de uma única pessoa. Assim a humanidade não anda. Quarto, a privacidade de quem sai à rua não pode ser considerada de igual quadrante da intimidade daquele que se mantém guardado em seu secreto quarto. Nem é que este não seja objeto de olhares. É que o seu dormente não abre a janela para resguardo pessoal constitucionalmente protegido. (grifo nosso).

A Min. Carmem Lúcia parece referendar a teoria de Robert Alexy quando comenta que "[...] o critério da ponderação para interpretação de normas e solução de casos nos quais são elas aplicadas não é inédita neste Supremo Tribunal Federal." Vale-se de uma conclusão de Joaquim Gomes Canotilho sobre os arts. 20 e 21 do Código Civil brasileiro, em que o autor português vê "[...] uma operação deôntica de proibição claramente inconstitucional."

Nada obstante, o recurso discursivo à proteção constitucional do direito à liberdade de expressão e do direito à informação, unido à proibição da censura, resulta na conclusão de que a autorização prévia para a biografia é uma censura particular. Com essa linha de pensamento, vota no seguinte sentido:

Ação direta julgada procedente para dar interpretação conforme a Constituição aos arts. 20 e 21 do Código Civil, sem redução de texto, para, em consonância com os direitos fundamentais à liberdade de pensamento e de sua expressão, de criação artística, produção científica, declarar inexigível autorização de pessoa biografada relativamente a obras biográficas literárias ou audiovisuais, sendo também desnecessária autorização de pessoas retratadas como coadjuvantes (ou de seus familiares, em caso de pessoas falecidas ou ausentes).

\section{Considerações Finais}

Após a reconstrução argumentativa, conclui-se que dos três argumentos levantados pela exordial da ANEL um não foi contemplado no voto condutor do julgamento: o argumento mercantil. O argumento libertário foi contemplado em parte na RJ1 e na RJ2. O STF se baseia na liberdade de expressão e no direito à informação, mas não se posicionou sobre a posição preferencial da liberdade de expressão. $\bigcirc$ argumento do pluralismo foi adotado em algumas passagens do acórdão e na RJ2. A $R J 3$ é uma construção das razões jurídicas antecessoras que confluem para a principal tese proposta na petição da ANEL: "[...] a dicção [dos artigos 20 e 21 do Código Civil] que lhes foi conferida acaba dando ensejo à proliferação de uma espécie de censura privada que é a proibição, por via judicial, das biografias não autorizadas."

Por fim, não obstante a explicitação, a análise e a discussão de inúmeros argumentos jurídico-constitucionais relevantes para o caso, entende-se que nesse acórdão o STF perdeu a oportunidade de enfrentar, adotando ou refutando, uma das linhas de raciocínio que autonomizam o direito 
fundamental à identidade pessoal, direito este de alguma forma já tangenciado pela doutrina portuguesa e espanhola (AMNISTÍA INTERNACIONAL, 1999; BARBAS, 1998, 1999; CERVILLA GARZÓN, 2001; CAMPS MERLO, 2007; CANOTILHO; MOREIRA, 2007; DOMÍNGUEZ GUILLÉN, 2003; GÓMEZ BENGOECHEA, 2007; GONZÁLEZ VEGA, 2003; HERNÁNDEZ DÍAZ-AMBRONA, 2005; LLAMAZARES FERNÁNDEZ, 1999; LÚCIO, 2001; OTERO, 1999; MIRANDA; MEDEIROS, 2005; TRABUCO, 2001).

Carvalho, Cardoso e Figueiredo (2005, p. 26), por exemplo, já defenderam que o direito à identidade pessoal inclui a proibição da elaboração de uma biografia não autorizada e o direito à verdade pessoal, que impede o uso indevido de atributos exclusivos de um indivíduo (um pseudônimo, um título). O direito à identidade pessoal em Portugal encontra previsão no artigo 26.1 da Constituição da República Portuguesa.

Ainda que não expressamente positivado no texto da Constituição Federal, no Brasil, já suscitaram-se vozes para o reconhecimento constitucional do direito à identidade pessoal, como Enéas Costa Garcia (2001), Raul Cleber Da Silva Choeri (2010) e Marco Aurélio Rodrigues da Cunha e Cruz (2012, 2015). O próprio STF, no Recurso Extraordinário n. 363889 (ação de investigação de paternidade e coisa julgada), já teve a oportunidade de refletir sobre o direito fundamental à identidade pessoal do indivíduo, quando o Ministro Luiz Fux exalta que esse direito se desdobra, dentre outros aspectos, na identidade genética, e tem seu núcleo essencial fulcrado na dignidade da pessoa humana. Entretanto, não avança para a possível relação entre o direito à identidade pessoal e as biografias.

\section{Referências}

AMNISTÍA INTERNACIONAL. El derecho a la propia identidad: la acción en favor de los derechos humanos de gays y lesbianas. Madrid: EDAI, 1999.

BARBAS, Stela Marcos de Almeida Neves. Direito à identidade genética. Forum Iustitiae - Direito \& Sociedade, v. 1, t. 6, p. 39 e ss., nov. 1999.

BARBAS, Stela Marcos de Almeida Neves. Direito ao património genético. Coimbra: Almedina, 1998.

CAMPOS, Diogo Leite de. Nós: estudos sobre o direito das pessoas. Coimbra: Almedina, 2004.

CAMPS MERLO, Marina. Identidad sexual y derecho: estudio interdisciplinario del transexualismo. Pamplona: Eunsa, 2007.

CANOTILHO, José Joaquim Gomes; MOREIRA, Vital. Constituição da República Portuguesa: anotada. 4. ed. Coimbra: Coimbra Editora, 2007. v. 1.

CARVALHO, Alberto Arons de; CARDOSO, Antônio Monteiro; FIGUEIREDO, João Pedro. Direito da Comunicação Social. 2. ed. rev e aument. Lisboa: Casa das Letras, 2005.

CERVILLA GARZÓN, María Dolores. Reflexiones en torno al nuevo derecho a la identidad sexual. Revista General de Derecho, Valencia, n. 89, p. 4947-4962, 2001. 
CHOERI, Raul Cleber da Silva. O direito à identidade na perspectiva civil-constitucional. Rio de Janeiro: Renovar, 2010.

CUNHA E CRUZ, Marco Aurélio Rodrigues da. A configuração constitucional do direito à própria imagem. Joaçaba: EdUnoesc, 2015.

CUNHA E CRUZ, Marco Aurélio Rodrigues da. Anotações sobre o Direito Constitucional à Própria Identidade. In: LUCCA, Newton de; MEYER-PFLUG, Samantha Ribeiro; NEVES, Mariana de Barboza Baeta (Org.). Direito Constitucional Contemporâneo. Homenagem ao professor Michel Temer. São Paulo: Quartier Latin, 2012. p. 477-494.

GARCIA, Enéas Costa. Direito à identidade pessoal. In: DINIZ, Maria Helena (Coord.). Atualidades Jurídicas. São Paulo: Saraiva, 2001. p. 165-197.

DOMÍNGUEZ GUILLÉN, Maria Candelaria. Sobre los derechos de la personalidad. Díkaion: revista de actualidad jurídica, Colombia: Universidad de la Sabana, n. 12, 2003. Disponível em: < http:// dikaion.unisabana.edu.co/index.php/dikaion/article/view/1248/1360>. Acesso em: 30 out. 2016.

GONZÁLEZ VEGA, Javier. Derecho a la identidad sexual: la posición del Tribunal Europeo de Derechos Humanos. Revista General de Derecho Europeo, Madrid: Portalderecho, n. 1, Mayo 2003. Disponível em: <http://www.iustel.com/v2/revistas/detalle_revista.asp?id_noticia $=401303 \& \mathrm{~d}=1>$. Acesso em: 20 out. 2016.

GÓMEZ BENGOECHEA, Blanca. Derecho a la identidad y filiación: búsqueda de orígenes en adopción internacional y en otros supuestos de filiación transfronteriza. Madrid: Dykinson, 2007.

HERNÁNDEZ DÍAZ-AMBRONA, María Dolores. Notas sobre el derecho a la identidad del niño y la verdad biológica. Revista de Derecho Privado, año 89, n. 4, p. 19-74, jul./ago. 2005.

LLAMAZARES FERNÁNDEZ, Dionisio. Derecho de la Libertad de Conciencia II - libertad de conciencia, identidad personal y derecho de asociación. Madrid: Civitas, 1999.

LÚCIO, Álvaro Laborinho. A genética e a pessoa - o direito à identidade. Separata da Revista do Ministério Público, v. 22, t. 88, p. 7-20, 2001.

MIRANDA, Jorge; MEDEIROS, Rui. Constituição Portuguesa Anotada. Coimbra: Coimbra Editora, 2005.

ORGANIZACIÓN DE LOS ESTADOS AMERICANOS. Comisión Interamericana de Derechos Humanos. Relatoría especial para la liberta de expresión. Estudio especial sobre el derecho de acceso a la información. Washington, 2007.

OTERO, Paulo. Personalidade e identidade pessoal e genética do ser humano: um perfil constitucional da bioética. Coimbra: Almedina, 1999.

TRABUCO, Cláudia. Dos contratos relativos ao direito à imagem. O Direito, ano 133, p. 389-459, abr./jun. 2001. 
